ISSN: 2637-4676

\title{
Rodent Control Strategies in Houses
}

\author{
Abd El Aleem* and Saad Soliman Desoky \\ Plant protection Department (Agriculture Zoology), Sohag University, Egypt
}

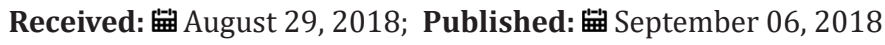

*Corresponding author: Plant protection Department (Agriculture Zoology), Faculty of Agriculture, Sohag University, Egypt

\begin{abstract}
Rats and mice are not only a nuisance but can also cause property damage and transmit diseases. You'll know they've arrived if you see rodent droppings near a food source or shredded fabric or paper. If you identify rodents, there are several steps to take to ensure permanent removal of these pests. Removing rodents with traps or poisons will not keep rodents out of your home in the future. To permanently keep rats and mice out of your home or business, you will need to prevent access by sealing all possible entry points. It is equally important to eliminate rodent attractions such as food and water by keeping food in tightly sealed containers and repairing leaky pipes.
\end{abstract}

\section{Introduction}

All rodents require food, shelter, and water. The shelter provides protection from predators, inclement weather, and a favorable place to bear and rear their young. Although rodents require water, those water requirements vary greatly by species. Because rodent food and cover (i.e., vegetation) can be influenced by human activities, there has been considerable development of strategies to reduce populations and damage by manipulating vegetation $[1,2]$. Use exclusion and sanitation tactics to get rid of rodents in a safe and cost-effective way. The most effective long-term solution is to keep rodents out in the first place. Measures such as sealing entry points prevent rodents from entering buildings and help you avoid a fullscale invasion. Follow the tips in the sections below and you will be one step closer to keeping your home permanently free of rats and mice (SRC).

\section{Common sources of food and water are attractive to rodents}

a) Food in unsealed containers such as bags of chips, rice, cereal, crackers, flour, and other non-perishables.

b) Pet food and water left out overnight or in a bag rather than in a secure container.

c) Fruits or vegetables in open bowls left outside of refrigerator.

d) Leaky pipes or faucets throughout the house.

e) Close trash (SRC).

\section{Common rodent access points}

a) Holes near cabinets, closets or doors leading to outside or crawl spaces.

b) Holes around sink or appliance pipes.

c) Cracked foundations in the basement or unscreened ventilation holes in the attic, especially in older structures.

d) Holes around windows or doors.

e) Missing screens in vents or crawl spaces under buildings.

f) Once you have blocked the access points and removed sources of food and water, you'll need to eliminate the remaining rodents. The following sections offer an overview of different treatment options and serve as useful guidance for keeping your home or business permanently free of rats and mice (SRC).

\section{Guidelines to Maintaining a Rodent-Free Home}

Three Guiding Principles:

\section{a) Prevent}

i. Seal entry points to prevent rodents from entering your home or business. Be sure to use 1/4" x 1/4" metal mesh to seal off existing entry points.

ii. Remove rodent attractions such as food or shelter by ensuring that food is securely stored and that surroundings are clean. 


\section{b) Identify}

i. Look for signs of rats and mice such as rodent droppings round food, kitchen corners, inside cabinets or under sinks.

ii. Also, look for nesting material such as shredded paper or fabric.

\section{c) Treat}

i. Remove rodents by using snap or electronic traps. Be cautious with live traps as rodents might urinate which increases the risk of spreading disease (SRC).

\section{Outdoor recommendations}

a) Don't plant ivy - it provides shelter and a food source for rodents: snails and slugs. Ivy on walls can form "rat ladders" to windows, attics and other interior spaces.

b) Keep compost piles as far away from structures as possible and grass cut to no more than two inches tall.

c) Maintain at least a 2-foot space between bushes, shrubs, fences, and buildings. Also, remove tree limbs within 3 feet of a structure or roof.

d) Avoid having a bird feeder since it provides a source of food for rodents.

e) Keep outdoor grills and cooking areas clean.

f) Keep firewood off the ground and as far away from structures as possible to mitigate shelter opportunities.

g) Use city-issue plastic trash bins. If cracked or missing a lid, contact the Department of Sanitation for a replacement (SRC).

\section{Indoor recommendation}

a) Encase all food items such as breakfast cereals, chips, and crackers in containers.

b) Opt for garbage bins and compost containers with a top that seals tightly.

c) Rinse food and beverage containers before discarding or recycling.

d) Clean your garbage and recycling bins frequently.

e) Do not leave pet food or water out overnight.

f) Maintain stove tops clean and free of food scraps.

g) De-clutter your home of papers, fabric, and any similar materials that attract rodents for nesting.

h) Repair leaky pipes.

i) Seal entry points around cabinets, interior walls, attic, and crawl spaces with steel wool, caulk, or $1 / 4^{\prime \prime} \times 1 / 4^{\prime \prime}$ metal mesh. j) Maintain attic, crawl spaces, and cabinets near sinks clean and free of moisture (SRC).

\section{Promote natural predators}

Natural predators such as cats, snakes, hawks, and owls can help to control rodent populations by feeding on rats and mice (SRC).

\section{Treating rodent infestation}

If you confirm that rats or mice are present in your home, you will need to use a combination of preventative measures and treatment options to get rid of them. The preventative measures include, removing food, water, shelter, and access to your home. This section will focus on the treatment options available and provide an overview of traps (SRC).

\section{Types of traps}

Benefits of using traps: Using traps instead of rodent poisons gives you clear confirmation of a captured rodent and allows you to better gauge the effectiveness of treatment. You are also able to dispose of rodents immediately rather than dealing with the foul odor of rotting carcasses from poisoned rodents inside your walls or otherwise out of reach. Most important, using traps allows you to avoid rodenticides, which pose a greater threat of exposure to children, pets, and non-target wildlife, including natural predators (SRC).

\section{Traps description}

Live-animal trap: This is a catch and release system that avoids killing a rat or mouse. Some states prohibit releasing rodents into the wild. The Center for Disease Control (CDC) warns that captured rats or mice might urinate and increase risk of spreading disease.

Snap trap: This is the oldest type of trap and uses a springloaded bar to kill a rodent on contact. Some modern snap traps prevent risk to children and pets by enclosing the device in a plastic box.

\section{Multiple-Catch Live Mouse Trap}

This is a catch and release system that allows for capture of multiple mice.

\section{Glue trap}

Glue traps are not recommended because the adhesive plate that is used to capture rodents can also trap birds, baby animals, lizards, and even pets. These traps also cause undue suffering to rodents. The CDC warns that captured rats or mice might urinate and increase the risk of spreading disease. Enclosure boxes are plastic boxes that can fit a single snap trap, sometimes more, in order to provide an additional layer of protection for kids and pets. These boxes also hide the dead rodent, making for easier disposal of rodent, and can be re-used (SRC). 


\section{Electronic trap}

This battery-powered trap delivers an electric shock that kills rodents quickly. This is a newer type of trap, and models are available for both rats and mice.

\section{When using traps, take the following safety steps}

Be sure to place traps in locations where children and pets cannot access them or place traps in safety enclosure boxes.

Cleaning up after trapping rodents: The Center for Disease Control (CDC) recommends the following safety tips:

a) Use gloves when disposing of dead rodents, nests, or any nesting material.

b) Spray the dead rodent or nesting material with a disinfectant solution and allow them to soak for 5 minutes before disposing rodent or materials in a secure plastic bag.

c) Spray and wipe up the area surrounding dead rodent or nesting material with a disinfectant.

d) Place the plastic bag with rodent or nesting material into another plastic bag along with any wipes or rags that were used to sanitize the surrounding area.

e) Be sure to wash your hands thoroughly with soap and water (SRC).

\section{Rodenticides}

a) Rodenticides consist of different types of poisons used to kill rodents. Rodenticide baits can be lethal for any mammal or bird that ingests them and are not only poisonous for rodents. As a result, all baits pose a high risk of poisoning for non-target animals that might eat the bait or consume a poisoned rat or mouse.

b) If you choose to use rodenticides, you should be ready to deal with these potential consequences:

c) Rodents are likely to die in locations where they cannot be retrieved. The smell of a dead animal will persist for several weeks to several months.

d) If you or your neighbors have cats or dogs, they may die or become acutely ill from eating poisoned rodents.

e) Predatory birds like hawks, eagles and owls, and mammalian predators such as foxes and coyotes may die from eating poisoned rodents or a rodenticide bait. f) Children are at risk of accidental poisoning since they might mistake the rodenticide bait for candy or food.

g) If after assessing the risks to children, pets, and wildlife of using rodenticides, you still determine that rodenticides are necessary, take these precautionary steps to reduce risk:

h) Always read and follow the label instructions on the pesticide product. The label is the law and you could be liable for any damage resulting from not following the label instructions.

i) Use only US EPA approved products that are sold and used with tamper resistant bait stations to protect children, pets, and wildlife. See US EPA's list of rodenticide bait station products here (EPA) [3].

j) Indoors, only place rodenticide bait stations in locations that are completely inaccessible to children and pets-inside walls, under heavy appliances, or in enclosed crawlspaces.

k) It is best to use anticoagulants because they are environmentally safe [4].

l) Once all signs of rodents are gone, remove bait stations promptly by placing in a secure plastic bag $[5,6]$.

\section{Achieving Success}

Preventing and treating rodent infestations requires a combination of eliminating access points rats and mice might use to enter your home, removing food sources and shelter that attract rodents, and using traps to get rid of existing rats and mice in or around your home. Using a multi-tactic approach to manage rodents decreases the risk of dealing with future infestations since a significant piece of the puzzle is adopting preventative measures such as blocking access and eliminating food and water sources that attract rats and mice (SRC) [7].

\section{References}

1. Barras SC, TW Seamans (2002) Habitat management approaches for reducing wildlife use of airfields. Proceedings of the Vertebrate Pest Conference 20: 309-315.

2. Desoky ASS (2007) Management strategies for rodents within different ecosystems. MSc Thesis Fac Agric Assiut Univ, pp. 124.

3. EPA, Environmental Protection Agency.

4. Desoky ASS (2016) Rodenticides (Anticoagulant) International Journal of Research Studies in Zoology (IJRSZ) 2(3): 1-6.

5. UCDIO, University of California, Davis IPM Online.

6. CDC, Center for Disease Control.

7. SRC, Safe Rodent Control https://t.co/6SOqjYp2M7. 


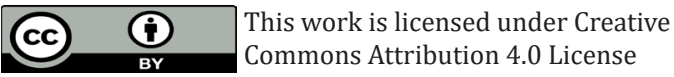

To Submit Your Article Click Here: Submit Article

DOI: 10.32474/CIACR.2018.04.000184

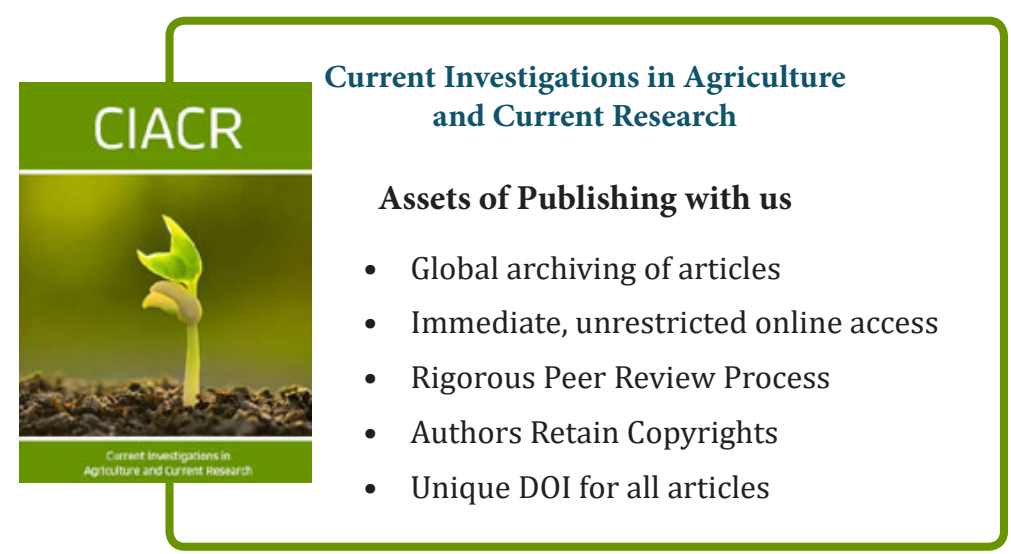

